\title{
Unable to Confirm Conditions of Use
}

National Cancer Institute

\section{Source}

National Cancer Institute. Unable to Confirm Conditions of Use. NCI Thesaurus. Code C118651.

Cannot verify the situation surrounding the condition in which something is used. 